\title{
MODIFICATION OF RACK-AND-PINION TRANSMISSION DESIGN WITH INCREASED RESOURCE
}

\author{
Oleg KROL, Volodymyr SOKOLOV, Aleksander GOLUBENKO \\ Volodymyr Dahl East Ukrainian National University, Department of Machinery Engineering and Applied \\ Mechanics, 59-a Central pr., Severodonetsk, 93400, Ukraine \\ e-mail: krolos.snu.edu@gmail.com
}

\begin{abstract}
In this paper, the mechanism of a slotting spindle head for the implementation of rectilinear motion based on a rack and pinion is considered. A three-dimensional modeling procedure of the slotting head elements for a multioperational machine tool of the drilling-milling-boring type has been carried out. 3D models of the rack and pinion were built in the integrated CAD KOMPAS using its built-in geometric core. An assessment of the stress-strain state in the engagement zone is given using the finite element method. The concept of increasing the load capacity due to the proposed version of the teeth envelope surface with curved axoids is analyzed. An analytical apparatus for determining the basic design parameters of a rack and pinion transmission modified version is proposed. The calculation of the geometric parameters for the end profile of the gearing teeth is experimentally realized, taking into account the found value of the disk milling cutter diameter for teeth cutting by the copying method.
\end{abstract}

Keywords: rack bar, solid model, basic rack profile, load capacity, curvilinear axoids.

\section{INTRODUCTION}

Rack-and-Pinion Transmission (RPT) is used on CNC machines to convert the reciprocating motion of the rack into the rotary motion of the pinion, and vice versa. The machining of rather large machine parts, which do not have high requirements for accuracy, is its area of application. The advantages of the RPT are its high efficiency (up to 99\%), resistance to stress, ease of operation and low susceptibility to contamination. Another option is to use it in interchangeable modular tooling of multioperational machines to increase its technological capabilities [1-3].

When designing rack-and-pinion transmission, one of the main requirements is to ensure strength characteristics with minimum dimensions. To research the RPT strength characteristics, using calculation forms RF-02-25 [4], intended to determine the static bending stress strength. For RPT heavily loaded engagement - the rack is checked for bearing stress. However, the considered formulas do not give an idea of the full picture of the stress-strain state of the RPT elements, the balance of various stress components in the rack tooth cross-sections and stress concentration zones.

The high level of stresses and strains in the process of functioning makes it necessary to search for ways of improving the design of the RPT elements and the technology of their manufacturing.
One of the research areas is a comprehensive analysis of the nature and conditions of gearing, as the basis for the implementation of a complex geometric-kinematic study of the RPT mechanism.

\section{LITERATURE REVIEW}

Several works [5-7] are devoted to the study of the functioning of the rack and pinion gear and the stress-strain state of its elements.

In work [5] the complex approach to an estimation of the dynamic quality of RPTfunctioning and level of contact and bending stresses in a zone of rack and gear wheel engagement is offered. At the initial stage of the research, 3D models of the RPT elements were built in the Unigraphics system. On this basis, research on the transmission dynamics in the system ANSYS was conducted and a set of natural frequencies of vibrations outside the resonance zone was determined. Using the finite element method, the diagrams (fields) of the equivalent contact and bending stresses in the gearing zone have been obtained. It is shown that the maximum level of stresses (in quantitative form) is located near the teeth addendum surface, outside the meshing zone, and the thesis about the necessity of modification of the toothed profile design is stated.

In [6] a rotary machine with a driving device in the form of a toothed rack and pinion mechanism is

(C) 2022 by the Authors. Licensee Polish Society of Technical Diagnostics (Warsow. Poland). This article is an open access article distributed under the terms and conditions of the Creative Commons Attribution (CC BY) license http://creativecommons.org/licenses/by/4.0/) 
considered. The work of the given mechanism analysis based on the built 3D model in the ANSYS system is carried out. The picture of contact and bending stresses distribution along the tooth profile is presented. The places of deformation concentration in the contact zone and the area of the tooth dedendum are revealed. To improve the service life of the RPT, the authors [6] propose to use aluminums alloys and composites as gear material, which are characterized by a lower level of deformation in the contact zone. At the same time, the issues of improving the design of the rack-andpinion mechanism are not considered in this work.

In the fundamental study [7] the mechanical system Rack-and-Pinion steering system (RPS), which is modeled using multibody modelling of the system (MBS) [7, 8]. The links between the elements of the system are mapped using kinematic constraints (joke assembly, tie rods) and force elements (pressure spring). As the core of MBS, the authors have developed a set of computational algorithms based on the equations of motion - rack rolling in longitudinal rack axis when engagement with a gear wheel. The use of the reverse engineering toolkit [7] is very effective for determining the geometric characteristics and constructing a model of elastic contact interaction. A distinctive feature of the proposed research [7] is the introduction of the RPS Coordinate measuring machine to obtain estimates of its functional behavior taking into account the measured geometry of the rack gear. On this basis, a new functional test for assessing the quality of the rack and pinion gearing is implemented.

In the same respect, the work [9] is of interest. On the example of toothed belt transmission, a device has been developed to measure the parameters of a toothed belt and changes in its transverse and longitudinal profile are assessed. Measurements along the axis are performed continuously and controlled by an application called DiagBeltSonic, specially developed for this purpose. The application allows the designer to determine some basic information about the structure of the main gear elements before testing. It is also important to equip gear production with appropriate CAM software systems. Promising in this regard is the Gleason 5-axis Gear Studio (G5S) [10] software from Gleason Corporation. These specialized programs are designed for tooth flank profiling, contact pattern evaluation, and preparation of appropriate control programs for 5-axis $\mathrm{CNC}$ machines and machining centers.

Issues of loading level analysis of RPS pinion at high gear ratios and limited dimensions of RPSmechanism using multibody modelling apparatus are also considered in [11]. The constructive variant of the small-diameter pinion with a reduced number of teeth and transmission correction associated with an increase in friction forces is analyzed in this paper. Technological and structural ways of torque reduction on the actuator RPS and reducing the level of stresses on the flank surfaces of the rack and pinion teeth are proposed.

In many works [12-14] it is necessary to realize at the initial stages of research to improve the toolkit description of the tooth flank surface contour of the wheel. Such a description will be the basis for obtaining optimized contact conditions in a wide range of gearing functioning. The study of contact lines, the curvature of working surfaces and localization of contact in works [12, 13] were considered. According to [14], one of the main goals at the initial stage is to create a working 3D model to analyze the contact geometry, visual identification and evaluation of the ratios of many tooth geometric parameters. The important parameters include groove profile characteristics, which are largely determined by the shape of the longitudinal generatrix of the pinion and wheel axoids.

Thus, a method of creating a three-dimensional model of gear transmissions in the relevant integrated CAD $[15,16]$ should be included in the designer's toolkit. The integrated CAD system KOMPAS-3D [17, 18] with application libraries and APM Graph module for parametric modeling of shafts and mechanical gears is promising in this regard.

Based on the analysis of the functioning process of RPT-mechanisms and the existing results, let's carry out the statement of the research problem: to develop an improved design of the rack-and-pinion transmission with an increased resource using the toolkit of three-dimensional and parametric modeling in the KOMPAS-3D system.

To achieve this goal, it is proposed:

1. To create three-dimensional models of the RPT for multi-operating machine tool using the author's parametric kernel of the ARM Graph module and to research the rack stress-strain state of the RPT-mechanism by the finite element method.

2. Develop analytical apparatus for calculating the main technical characteristics of the modified RPT design with increased service life.

\section{3D AND PARAMETRIC MODELING OF RPT-MECHANISM AND RESEARCH OF THE STRESS-STRAIN STATE}

\subsection{Design of a slotting spindle head}

A Rack-and-pinion transmission is used in planning, gear slotting machines and machining centers to convert the rotational motion of the driving link into a straight motion of the driven link.

Machining centers of the drilling and milling and boring group with a horizontal spindle (structural formula of which is XYZOC $\hat{C}_{\mathrm{h}}$ are using a variety of modular equipment $[19,20]$. To increase the number of technological modules and increase the degree of use of the layout structure overhead heads, turning devices, as well as a slotting head ( $\mathrm{SH})$ are used. The $\mathrm{SH}$ kinematic scheme is shown in Fig. 1, a. 
In the SH-design (Fig. 1, b) which is mounted on the horizontal spindle headstock with the help of four screws, gear-and-rack transmission is used. The SH drive is realized from the main motion drive shaft through the cam clutch, gear transmission and then through the connecting link mechanism which the follower is connected to the ram performing a double pass $\left(d_{p}\right)$ per one-wheel revolution of the connecting link mechanism. The dependence of the number of ram double pass $n_{d p}$ on the vertical spindle rotation frequency $n_{\mathrm{sp}}$ is determined by the formula: according to which one double stroke of the ram corresponds to a value equal to 2.51 spindle revolutions.

\subsection{Construction of $3 D$ models of the slotting spindle head}

To analyze the effectiveness of the design and to select the optimal variant of the slotting head (SH) design of a CNC multioperational machine tool model SF68VF4 [21, 22], a 3D model has been created in the CAD environment KOMPAS-3D (Fig. $1)$. In the system outline, there is a set of software, including applications for building 3D models for a variety of shafts and mechanical gears. The development of a rather complex SH design is based on the capabilities of the C3D Modeler geometric kernel [18]. The C3D modeler is designed to build

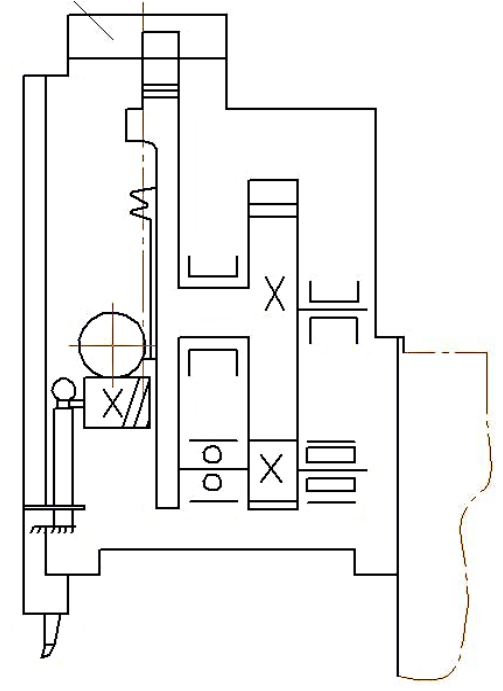

a a geometric model and calculate the geometric characteristics of the simulated object. The new version of the $\mathrm{C} 3 \mathrm{D}$ Modeler used in this research includes functionality to remove holes and rounding from the model (Fig. 2, b). This leads to a simplified representation of the 3D model, which is prepared for further calculation in the CAE system [23, 24].

Another application of the new function is a modification of rounding (Fig. 2, b). Not only CAE developers but also creators of CAD/CAM systems based on the C3D Modeler geometrical kernel will appreciate the presence of this operation.

\subsection{Rack bar parametric modeling in the module ARM Graph}

Profile and dimensions of a rack bar are defined by a basic contour (BC) following with GOST (Standard) 13755-2015 [25]. The BC dimensions predetermine the dimensions of the rack teeth: the thickness of the teeth $S_{n}$; the height of the dividing head $H_{a}$; the height of the tooth $h$, etc.

To ensure smooth mating of teeth during an engagement, the basic contour with the modified profile of the tooth head is used. In the process of teeth cutting the cut flank of the tooth profile near the addendum circle of the wheel is formed.

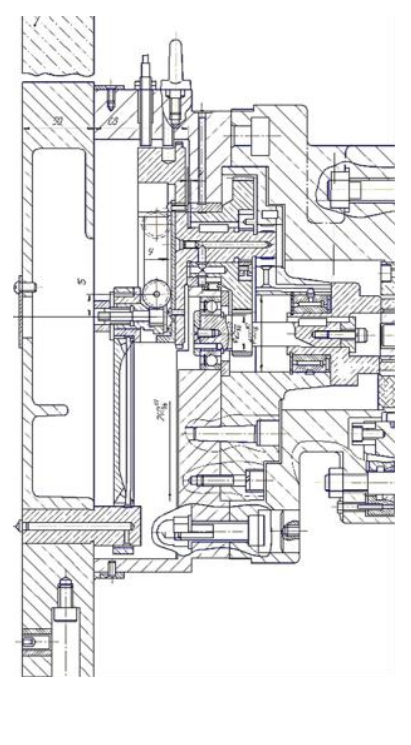

b

Fig. 1. 3D models of the main movement drive for the multi-purpose machine: $a$ - kinematics; $b$ - design

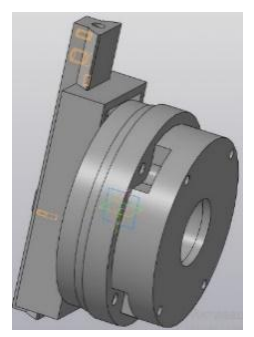

a

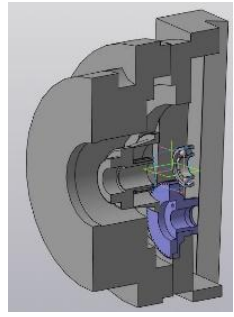

b

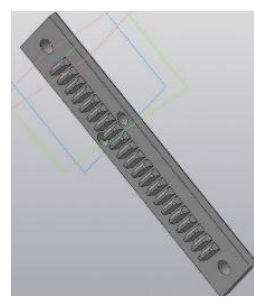

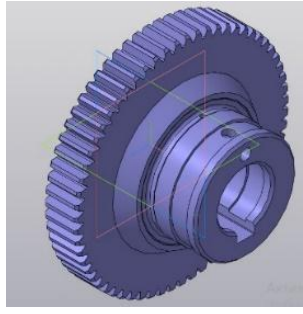

d

Fig. 2. Solid models of the slotting head: $\mathrm{a}$ - general view; $\mathrm{b}$ - cross-section $\mathrm{c}-$ gear rack; $\mathrm{d}-$ gear wheel 
Standard 13755-81 regulates the values of modification parameters - height coefficient $h_{\mathrm{g}}^{*}$ (not more than 0,45 ) and depth coefficient $\Delta^{*}$.

For more productive construction of $\mathrm{BC}$ rack bar and gear cutting tool it is advisable to use the parameterization apparatus in the environment of APM Graph module [26, 27]. Parametric models of BC rack bar were built in this module (Fig. 3, a and Fig. 3, b). With a minimum number of initial parameters of the cut gear (variable window), all derived data in the command window are defined.

The creation of the forming closed contour of the prismatic rack bar will be considered in the example of the slotting head for the machine model SF68VF4 (Fig. 1). The initial data are: module $m=1 \mathrm{~mm}$; the normal basic contour according to Standard 1375581; accuracy degree according to Standard 10242-819-B; tooth thickness $S_{n 0}=1.387^{-0,120} \mathrm{~mm}$; measuring height $h_{a 0}=0,748 \mathrm{~mm}$; number of teeth $z=21$.

In the module APM Graph the creation of the parametric model of the rack bar is carried out by using 3D operations:

- creating the generatrix contour of the tooth surface under the above initial data (Fig. 3, c);

- pulling out the generatrix contour of the rack

prismatic rod in both directions to obtain a model of the rack base (Fig. 3, d).

- pulling of generatrix contour of teeth profile with

basic contour according to Standard 13755-81 to obtain a solid model of rack tooth profile (Fig. 4, d).

The efficiency of the considered procedure is connected with the use of specialized graphic primitives of generatrix contours, systematized in the corresponding database of parametric data of the system.

\subsection{Estimation of the stress-strain state level of the rack bar}

The application of calculation formulas [4] does not give a complete picture of the stress-strain state of the rack-and-pinion engagement. To obtain such estimates, we will use the numerical finite element method (FEM) in the APM FEM module of solid and surface modeling integrated into the KOMPAS-3D system [22, 24]. This method can sufficiently describe both the geometry of the structure and the nature of the loadings applied to it and the material properties of the structure [28].
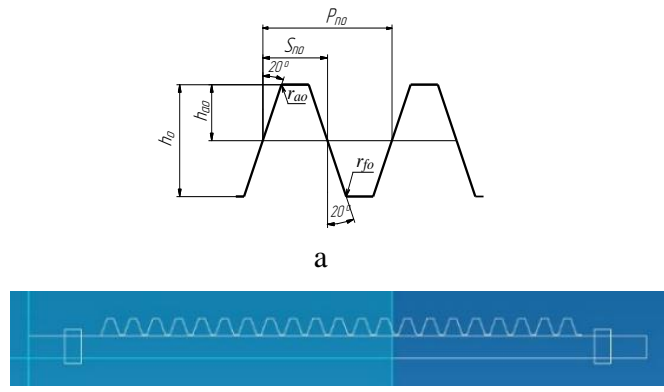

The APM FEM module is based on its geometric kernel. The system includes built-in finite element mesh generators with an automatic procedure for generating 4-node tetrahedron finite elements. A built-in finite element mesh generator has an automatic "enhancer" which ensures that predominantly equilateral triangles are used as finite elements, which are optimal in terms of minimizing the error of stress-strain calculations.

The module uses an algorithm for partitioning into volume elements in the mode of auto-selecting the maximum length of the element side, the maximum concentration coefficient and the rarefaction coefficient in the volume;

Let us consider the sequence of procedures of strength level analysis implementation of the rack bar in the APM FEM module. At the initial stage, the fastening and the main types of loadings applied directly to the elements of the three-dimensional model are set, and then the model is partitioned into finite elements (Fig. 4, a).

At the stage of complex strength analysis, conducted in the APM FEM module, determination of the geometric parameters of the structure, which provide the required safety factors, is implemented for the given external and internal impacts. The fields of equivalent stresses in Fig. 4, b, (calculated following the Mises hypothesis - energy theory of strength) in the cross-sections of the rack tooth allow us to conclude about the permissible level of plastic deformation $[24,29,30]$. Similarly, we can conclude about the level of principal stresses (only normal stresses acting on the faces of elementary crosssections), presented in Fig. 4, c.

In the complex stress state, the highest bending stresses are formed at the tooth root in the zone of transition of the generatrix of the main rack profile into the transition curve. The stress concentration in this zone can be reduced by increasing the radius of curvature of transition curve $\rho_{f}$ (if it does not violate the correctness of engagement in the transmission) [31]. The second way to reduce the concentration is to modify the tooth head profile of the basic contour (if the part value the of the end overlapping coefficient, defined by sections of the main profiles $\varepsilon_{a M}$, will appear less than $\varepsilon_{a M}=1.1$ at spur gearings and less than $\varepsilon_{a M}=1.0$ at helical gearings).

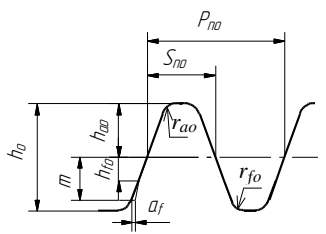

b

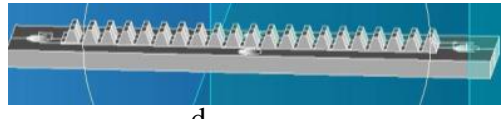

d

Fig. 3. Construction of the rack bar parametric model in the module ARM Graph: a - normalized BC; $\mathrm{b}$ - modified $\mathrm{BC} ; \mathrm{c}-2 \mathrm{D}$ generatrix contour; $\mathrm{d}$ - pulling out the generatrix contour 


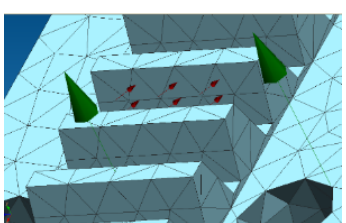

a

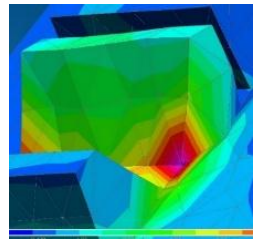

c

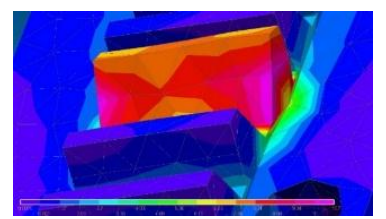

$\mathrm{b}$

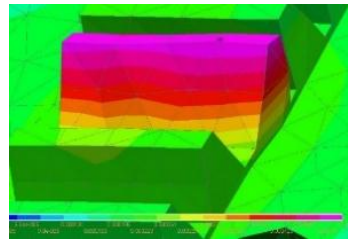

$\mathrm{d}$

Fig. 4. Results of strength calculation of rack: $a-$ finite-element mesh; $b$ - equivalent stress $\left(\sigma_{e m a x}=14.56 \mathrm{MPa}\right)$; $\mathrm{c}$ - principal stress field $\left(\sigma_{\mathrm{pmax}}=10.51 \mathrm{MPa}\right) ; \mathrm{d}-$ displacement field $\left(y_{\max }=0.105 \mathrm{~mm}\right)$

The field of deformations, presented in Fig. 4, d allows to concluding about insignificant in magnitude displacements in separate sections of the tooth (the displacements shown on the field of deformations are proportional to real ones), numerical values of which are presented on a digital scale.

\section{RESULTS AND DISCUSSION}

\subsection{Theoretical part}

As shown above, the issue of reducing the level of stress and improving the service life of the gear transmission through structural modification is an urgent task.

In this paper, a structural variation of the rackand-pinion transmission with increased load capacity is proposed, which is supported by the previously obtained patent solution [32].

As is known, the most common method of cutting the rack teeth (Fig. 2) is carried out by copying with a disk cutter with rectilinear cutting edges. As a result, the surface of the rack teeth is formed, which in the coordinate system $S_{1}\left\{X_{1}, Y_{1}, Z_{1}\right\}$ rigidly connected with the rack bar, is described by the equation:

$$
\begin{aligned}
& \vec{r}_{1}=(0.33 \cdot m+u \cdot \sin \alpha) \cdot \vec{i}_{1}+ \\
& +\left[r_{m c}-1.25 \cdot m-\left(r_{m c}-u \cdot \cos \alpha\right) \cdot \cos v\right] \times \\
& \times \vec{j}_{1}+\left(r_{m c}-u \cdot \cos \alpha\right) \cdot \sin v \cdot \vec{k}_{1},
\end{aligned}
$$

where $[u, v]-$ the independent variables defining the coordinates of a point on the rack tooth surface; $m$ - the rack transmission module; $r_{m c}$ - the nominal radius of the milling cutter; $\alpha=20^{\circ}$ - the angle of the cutting edges on the milling cutter.

The axial profile of the rack teeth is defined by the system of equations:

$$
\begin{aligned}
& X_{1}=0.33 \cdot m+u \cdot \sin \alpha ; \\
& Y_{1}=r_{m c}-1.25 \cdot m-\left(r_{m c}-u \cdot \cos \alpha\right) \cdot \cos v ; \\
& v=\arcsin \left(\frac{ \pm 0.5 \cdot b_{W}}{r_{m c}-u \cdot \cos \alpha}\right),
\end{aligned}
$$

where $b_{W}$ - width of the tooth ring pinion. The definition of the parameter is given below.
The pinion tooth surface is the envelope of the rack tooth surface in relative motion. By successive transition from the rack coordinate system $S_{1}$ to the coordinate system $S_{2}\left\{X_{2}, Y_{2}, Z_{2}\right\}$, associated with the rotating pinion: $S_{1} \rightarrow S_{01} \rightarrow S_{02} \rightarrow S_{2}$ (Fig. 5) using the matrix method of coordinate transformation, we obtain $[12,13]$ :

$$
\vec{r}_{2}=\left|\begin{array}{cccc}
\cos \varphi_{2} & -\sin \varphi_{2} & 0 & r_{2} \cdot\left(\varphi_{2} \cdot \cos \varphi_{2}+\right. \\
& & & \left.+\sin \cos \varphi_{2}\right) \\
\sin \varphi_{2} & \sin \varphi_{2} & 0 & r_{2} \cdot\left(\varphi_{2} \cdot \sin \varphi_{2}\right. \\
& & & \left.-\cos \varphi_{2}\right) \\
0 & 0 & 0 & 1 \\
0 & 0 & 0 & 1
\end{array}\right| \cdot \vec{r}_{1} .
$$

In the parametric form [33], dependence (3) will appear as:

$$
\left\{\begin{array}{l}
X_{2}=\left(0.33 \cdot m+u \cdot \sin \alpha+r_{2} \cdot \varphi_{2}\right) \cdot \cos \varphi_{2}- \\
-\left[r_{m c} \cdot(1-\cos v)+u \cdot \cos \alpha \cdot \cos v-\right. \\
-m \cdot(0.5 \cdot z+1.25] \cdot \sin \varphi_{2} \\
Y_{2}=\left[r_{m c} \cdot(1-\cos v)+u \cdot \cos \alpha \cdot \cos v-\right. \\
-m \cdot(0.5 \cdot z+1.25] \cdot \cos \varphi_{2}+ \\
+\left(0.33 \cdot m+u \cdot \sin \alpha+r_{2} \cdot \varphi_{2}\right) \cdot \sin \varphi_{2} \\
Z_{2}=\left(r_{m c}-u \cdot \cos \alpha\right) \cdot \sin v
\end{array}\right.
$$

Limits of change in the independent variables:

$$
\begin{aligned}
& u=[0 ; 2.25 \cdot m / \cos \alpha] \\
& v=\arcsin \left(\frac{ \pm 0.5 \cdot b_{W}}{r_{m c}-u \cdot \cos \alpha}\right) .
\end{aligned}
$$

The limits of variation of these variables are determined from the following conditions [30]. The linear parameter defines the moving of a point on a profile of the cutter from its top $\left(u=u_{\min }=0\right)$ to a root of a rack tooth in height $h=2.25 \cdot m$ given a slope of cutting edges $\alpha=20^{\circ}\left(u=u_{\max }=h / \cos \alpha\right)$. The angular parameter $v$ is found from the condition that the coordinate $Z_{2}$ is limited by the width of the tooth ring pinion $b_{W}$, that is, $Z_{2}=\left[-0.5 \cdot b_{W} ;+0.5 \cdot b_{W}\right]$.

Equations (4) describe the family of tooth surfaces of the rack in its motion relative to the pinion axis point $\mathrm{O}_{2}$. To obtain their enveloping surface, that is, 
the surface of the rotating pinion teeth in a coordinate system rigidly connected with it, let us compose the equation of engagement $F\left(u, v, \varphi_{2}\right)=0$ "rack $\leftrightarrow$ pinion", using the kinematic method:

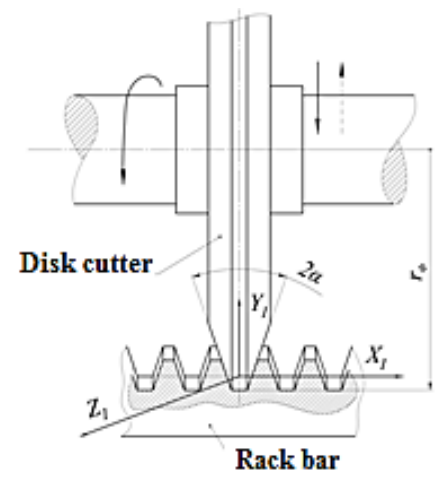

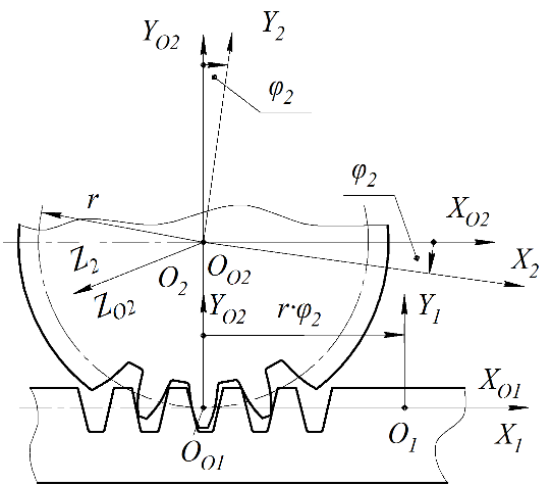

b

Fig. 5. Cutting of rack teeth: $a$ - cutting scheme; $b$ - the transition of a coordinate system

$$
\vec{n}_{1} \cdot \vec{V}_{1}^{(12)}=0
$$

where $\quad \vec{n}_{1}=n_{X 1} \cdot \vec{\imath}_{1}+n_{Y 1} \cdot \vec{\jmath}_{1}+n_{Z 1} \cdot \vec{k}_{1}$ normal vector to tooth surface of the rack; $\vec{V}_{1}^{(12)}=$ $\vec{V}_{1}^{(1)}-\vec{V}_{1}^{(2)}$ - vector of relative velocity.

Omitting substitution of values $\vec{n}_{1}$ and $\vec{V}_{1}^{(12)}$, and further transformations, let us write equation (6) in expanded form:

$$
\begin{aligned}
& r_{m c}-\left(r_{m c}-u \cdot \cos \alpha\right) \cdot \cos v-1.25 \cdot m+ \\
& \left(r \cdot \varphi_{2}+0.35 \cdot m+u \cdot \sin \alpha\right) \cdot \sin \alpha=0,
\end{aligned}
$$

where $r=0.5 \cdot m \cdot z-$ the pitch radius of the rack; $z$ - the number of the rack teeth.

Hence express the third variable $-\varphi_{2}$, through other two $-[u, v]$, that is, find $\varphi_{2}=\varphi_{2}(u, v)$ :

$$
\begin{aligned}
& -\left[r_{m c}-\left(r_{m c}-u \cdot \cos \alpha\right) \cdot \cos v-\right. \\
& \varphi_{2}=\frac{-1.25 \cdot m]-(0.35 \cdot m+u \cdot \sin \alpha) \cdot \sin \alpha}{r \cdot \sin \alpha} .
\end{aligned}
$$

The joint consideration of (4) and (8) is the equation of the enveloping surface $\vec{r}_{2}=\vec{r}_{2}(u, v)$, that is, the equation of the pinion teeth surface.

Based on the proposed procedure for the development of a modified rack-and-pinion transmission in the CAD environment is created its three-dimensional model (Fig. 6).

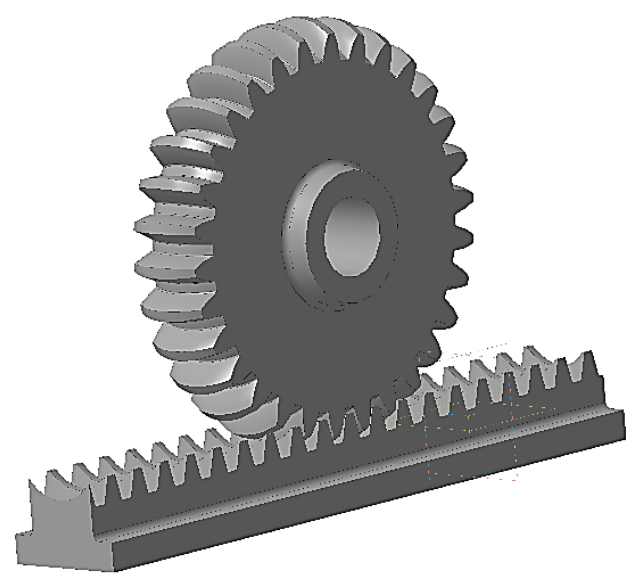

Fig. 6. Three-dimensional model of the modified rack-and-pinion transmission

\subsection{Experimental part}

To build the face profile of the pinion teeth it is sufficient to calculate the coordinates $X_{2}$ and $Y_{2}$, using the system of equations (4), (2,c) and (8).

The nominal diameter of the milling cutter [30] is chosen taking into account the following constraint: $r_{O}>0.5 \cdot b_{W}$, Fig. 7. By introducing a safety factor $k>1$, this constraint can be represented in the form of equality:

$$
r_{O}=0.5 \cdot k \cdot b_{W}
$$

The radii $r_{m c}$ and $r_{O}$ are connected by the tooth height $h=2.25 \cdot m$, Fig. 7, therefore:

$$
r_{O}=r_{m c}-2,25 \cdot m \text {. }
$$

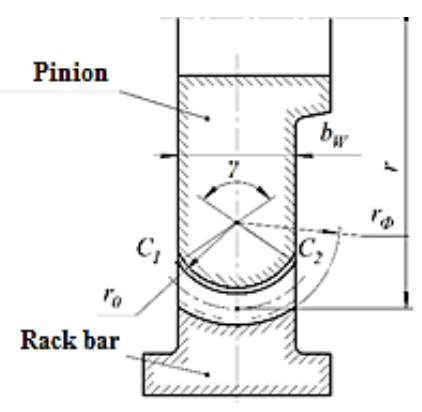

Fig. 7. To calculate the nominal diameter of the milling cutter

Since the left parts of equations (9) and (10) are equal, we equate their right parts. As a result, the minimum possible value $r_{m c}=r_{m c(\min )}$ for the specified value $k$ :

$$
r_{m c(\min )}=0.5 \cdot k \cdot b_{W}+2.25 \cdot m
$$

It is finally assumed that $r_{m c} \geq r_{m c(\min )}$.

For a transmission with parameters $m=4 \mathrm{~mm} ; b_{W}=$ $85 \mathrm{~mm}$ at $k=1.2: r_{m c(\min )}=0.5 \cdot 1.2 \cdot 85+2.25$. $4=56 \mathrm{~mm}$.

It is possible to recommend $k \approx 1.2 \ldots 1.4$.

The bending strength of the teeth in the proposed version of the rack-and-pinion transmission will be higher than in the conventional transmission. This is explained by the fact that with the same pinion width $b_{W}$, the length of the teeth in the rack transmission 
with curved axoids, $L_{O}=\cup C_{1} C_{2}$ (Fig. 6) will be greater than in the transmission in normative form [30], where tooth length $L_{W}$ and width $b_{W}$ coincide: $L_{W}=b_{W}$. The ratio $L_{O} / L_{W}$ is mainly responsible for the amount of bending stress reduction in the teeth of the proposed rack transmission in comparison with the transmission [30]:

$$
\begin{aligned}
& L_{O} / L_{W}=\frac{r_{O} \cdot \gamma}{b_{w}}= \\
& =2 \cdot \frac{r_{m c}-2.25 \cdot m}{b_{W}} \cdot \arcsin \left(\frac{0.5 \cdot b_{W}}{r_{m c}-2.25 \cdot m}\right) .
\end{aligned}
$$

For a transmission with the parameters given above, at $r_{m c}=70 \mathrm{~mm}>r_{m c(\min )}=56 \mathrm{~mm}$ (which corresponds to $k=1.25$ ), the ratio $L_{O} / L_{W}$ :

$$
\begin{aligned}
& L_{O} / L_{W}=2 \cdot \frac{70-2.25 \cdot 4}{85} \times \\
& \times \arcsin \left(\frac{0.5 \cdot 85}{70-2.25 \cdot 4}\right) \approx 1.11,
\end{aligned}
$$

that is, for the given parameters of the gear and the disc cutter, the bending stress in the teeth will be reduced by about $11 \%$.

\section{CONCLUSION}

A set of three-dimensional models of a slotting spindle head with a driven RPT mechanism in the integrated CAD system KOMPAS-3D has been developed. During 3D model creation, the KOMPAS application "Shafts and Mechanical Transmissions3D" based on the geometric kernel C3D Modeler was used, which significantly increased the designer's productivity.

Parametric models of rack bar were created in the APM Graph module, which operates with specialized graphic primitives of the tooth basic contours for the gearing elements. Parametric representation of the model, along with considerable reduction of modeling time, allows effectively solving multivariate gearing tasks of design.

The analysis of the stress-strain state in the rackand-pinion engagement zone by the finite element method in the APM FEM module has been carried out. The fields of stresses and displacements in the RPT contact zone have been obtained. It is revealed that the highest bending stresses in a complex stress state are formed at the tooth root in the transition zone of the main rack profile generatrix in the transition curve. This stress level can be reduced by increasing the transition curve radius of curvature at the tooth root.

A modified design of gearing with an increased service life by using the curvilinear form of the rack and pinion axoids has been developed. This development is based on the obtained analytical dependencies required for the complex geometrical and kinematic research of the proposed modified transmission on the one hand and the new patent solution on the other.
The reduction of bending stresses in the rack and pinion teeth with modified axoids has been proved by calculation. The main criterion for assessing the reduction of stresses is the ratio of tooth lengths of the modified and traditional construct is used for a specific design option. In the proposed version of the modified transmission with the given parameters of the milling cutter, the bending stress in the teeth will be reduced by about $11 \%$.

Author contributions: research concept and design, O.K., V.S., A.G.; Collection and/or assembly of data, O.K., V.S., A.G.; Data analysis and interpretation, O.K., V.S., A.G.; Writing the article, O.K., V.S., A.G.; Critical revision of the article, O.K., V.S., A.G.; Final approval of the article, O.K., V.S., A.G.

Declaration of competing interest: The authors declare that they have no known competing financial interests or personal relationships that could have appeared to influence the work reported in this paper.

\section{REFERENCES}

1. Knight WA, Boothroyd G. Fundamentals of metal machining and machining tools. Boca Raton, Florida: CRC Press; 2005.

2. Avramova TM, Bushuev VV, Gilova LY. Handbook on metal-cutting machine tools. Moscow: Mashynostroenye; 2012. Russian.

3. Dervoort WH. Modern Machine Shop Tools, Their Construction, Operation and Manipulation, Including Both Hand and machine Tools. London: Creative Media Partners, LLS; 2018.

4. Matsievsky AG, Ehrlich LB. Rationalization of calculations in the design of machine tools. Moscow: Mashynostroenye; 1971. Russian.

5. Xiao Y, He L, Zhu J, Xiao Y. Dynamic analysis of gear and rack transmission system. The Open Mechanical Engineering Journal 2014; 8: 662-667. https://doi.org/10.2174/1874155X01408010662.

6. Vavhal P, Shivam S, Harshal M, Jueli L, Suraj N. Design snd development of rack and pinion for $180^{\circ}$ flipping machine. Int. Res. J. of Science \& Engineering, 2018;A2: 272-275.

7. Morano D, Pellicano F. Modelling and simulation of rack-pinion steering systems with manufacturing errors for performance prediction. Int. J. Vehicle Systems Modelling and Testing 2018; 13(2): 178-198.

8. Li S. 'Effects of machining errors, assembly errors and tooth modifications on loading capacity, load-sharing ratio and transmission error of a pair of spur gears. Mechanism and Machine Theory 2007; 42 (6): 698-726. https://doi.org/10.1016/j.mechmachtheory.2006.06.002

9. Błażej B, Jurdziak L, Kirjanów A, Kozłowski T. A device for measuring conveyor belt thickness and for evaluating the changes in belt transverse and longitudinal profile. Diagnostyka 2017; 18(4): 97-102.

10. Gaiser U. 5-axis gear manufacturing gets practical. Geartechnology 2017:32-34.

11. Kamble N, Saha S. Effect of Pinion Profile Modification on Rack and Pinion Steering Gear. SAE Technical Paper 2005-01-1273, 2005. https://doi.org/10.4271/2005-01$\underline{1273}$

12. Litvin FL, Fuentes A. Gear geometry and applied theory. Cambridge: University Press; 2004. 
13. Litvin FL, Qi F, Fuentes A. Computerized design, generation, simulation of meshing and contact of facemilled formate cut spiral bevel gears. NASA/CR-2001.

14. Bjionowski B. A practical approach for modelling a bevel gear. Geartechnology 2015: 68-75.

15. Shevchenko S, Mukhovaty A, Krol O. Gear transmission with conic axoid on parallel axes. In: Radionov A, Kravchenko O, Guzeev V, Rozhdestvenskiy Y. (eds) Proceedings of the 5th International Conference on Industrial Engineering (ICIE 2019). ICIE 2019. LNME. Springer, Cham. (2020). https://doi.org/10.1007/978-3-030-22041-9 1

16. Krol O, Sokolov V. Research of modified gear drive for multioperational machine with increased load capacity. Diagnostyka 2020;21(3):87-93. https://doi.org/10.29354/diag/126026

17. Ganin NB. Three-dimensional Design in KOMPAS3D. Moscow: DMK Publishing; 2012. Russian.

18. Kamnev A. C3D Labs represents the C3D Toolkit 2017. Topical technologies for developers of engineering software. Isicad 2017; 154: 12-18.

19. Kotliar A, Basova Y, Ivanov V., and all. Ensuring the economic efficiency of enterprises by multi-criteria selection of the optimal manufacturing process. Management and Production Engineering Review 2020;11(1):52-61. https://doi.org/10.24425/mper.

20. Krol O, Sokolov V. Modeling carrier system dynamics for metal-cutting machines. International Russian Automation Conference (RusAutoCon). IEEE, Sochi. 2018;1-5.

https://doi.org/10.1109/RUSAUTOCON.2018.8501799

21. Nikonov VV. KOMPAS 3D. Creation of models., St. Petersburg: Peter; 2020. Russian.

22. Chagina AV, Bolshakov VP. 3D modeling in KOMPAS-3D v17 and higher. Textbook for universities. St. Petersburg: Peter; 2021. Russian.

23. Krol O, Sokolov V. Research of toothed belt transmission with arched teeth. Diagnostyka 2020; 21(4): 15-22. https://doi:10.29354/diag/127193

24. Magomedov A, Alechin A. Integrated finite element analysis in KOMPAS-3D. CAD/CAM/CAE observer 2010; 8(60): 1-5.

25. GOST 13755-2015. Basic norm of interchangeability. Cylindrical gears for general and heavy engineering. Standard basic racks tooth profile.

26. Krol O, Porkuian O, Sokolov V, Tsankov P. Vibration stability of spindle nodes in the zone of tool equipment optimal parameters. Comptes rendus de l'Acade'mie bulgare des Sciences 2019; 72(11): 1546-1556. https://doi.org/10.7546/CRABS.2019.11.12.

27. Zamry AA. Practical training course CAD/CAE/APM WinMachine. Teaching-methodical manual. Moscow: APM Publishing; 2007. Russian.

28. Krol O, Sokolov V. 3D modelling of angular spindle's head for machining centre. J. Phys. Conf. Ser., 2019; 1278:012002. https://doi.org/10.1088/17426596/1278/1/012002

29. Demianenko M, Volf M, Pavlenko I, Liaposhchenko O. Experimental studies on oscillation modes of vibration separation devices. Journal of Engineering Sciences, 2021;8(1):D1-D9.

https://doi.org/10.21272/jes.2021.8(1).d1]

30. Verbovyi A, Khomenko V, Neamtu C, Pavlenko V, Cherednyk M, Vashyst B, Pavlenko I. Parameter identification of nonlinear bearing stiffness for turbopump units of liquid rocket engines considering initial gaps and axial preloading. Journal of
Engineering Sciences, 2021;8(2): D8-D11. https://doi.org/10.21272/jes.2021.8(2).d2

31. Demianenko M, Starynskyi O, Pavlenko I, Sklabinskyi V, Trojanowska J, Skydanenko M, Liaposhchenko O, Ivanov V. Impact of dynamic characteristics of gears on the reliability of prilling equipment. In: Knapcikova L, Peraković D, Perisa M, Balog M. (eds) Sustainable Management of Manufacturing Systems in Industry 4.0. Springer, Cham. 2022. https://doi.org/10.1007/978-3-030-90462-3

32. Pat. 120218 Ukraine, F16H1/08 Rack gear. Shevchenko SV, Mukhovatiy OA, Krol OS, Khmelnitsky A. Application. 28.04.2017; Published 25.10.2017, Bulletin No. 20.

33. Mechanical engineering. Encyclopedia. In 40 vol. vol. IV-1. Machine parts. Structural strength. Friction, wear, lubrication. Ed. D.N. Reshetov. Moscow: Mechanical Engineering; 1995. Russian.

Received 2021-10-24

Accepted 2022-01-19

Available online 2022-01-20

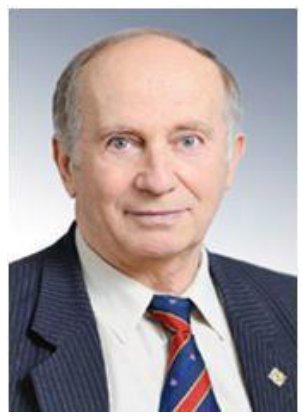

Oleg KROL (ORCID 00000003-0193-2750), PhD,

Professor of the Machinery engineering and applied mechanics department of the Volodymyr Dahl East Ukrainian National University, Severodonetsk, Ukraine. Main directions of scientific research: 3D- and parametrical modelling, machine tool design, CAD/CAM/CAE system, optimization in mechanical engineering, mechanical on reliability

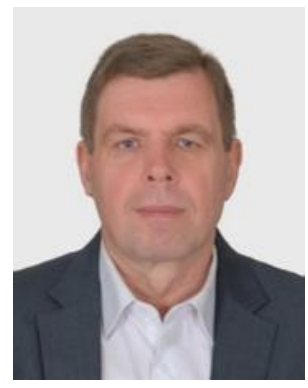

Volodymyr SOKOLOV (ORCID 0000-0003-04591824), Doctor of Sciences, Head of the Machinery engineering and applied mechanics department of the Volodymyr Dahl East Ukrainian National University, Severodonetsk, Ukraine.

Main directions of scientific research: automatic drives of technological equipment, dynamics and regulation of technological systems.

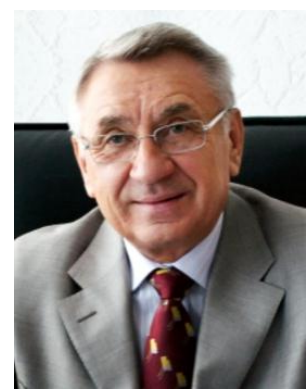

Aleksander GOLUBENKO (ORCID 0000-0002-2221-

6756), Doctor of Sciences, Professor of the Volodymyr Dahl East Ukrainian National University, Severodonetsk, Ukraine.

Main directions of scientific research: railway transport, mechanical engineering. 